\title{
Complete Placenta Previa: Ultrasound Biometry and Surgical Outcomes
}

\author{
Alison C. Wortman, MD ${ }^{1}$ Stephanie L. Schaefer, MD ${ }^{1}$ Donald D. Mclntire, PhD ${ }^{1}$ \\ Jeanne S. Sheffield, MD ${ }^{1}$ Diane M. Twickler, MD ${ }^{1,2}$ \\ ${ }^{1}$ Department of Obstetrics and Gynecology, University of Texas \\ Southwestern Medical Center, Dallas, Texas \\ 2 Department of Radiology, University of Texas Southwestern Medical \\ Center, Dallas, Texas \\ Address for correspondence Alison C. Wortman, MD, Department of \\ Obstetrics and Gynecology, University of Texas Southwestern Medical \\ Center, 5323 Harry Hines Boulevard, Dallas, TX 75235-9032 \\ (e-mail: Alison.Wortman@shcr.com).
}

Am J Perinatol Rep 2018;8:e74-e78.

\begin{abstract}
Objective To evaluate the relationship between surgical outcomes and ultrasound measurement of placental extension beyond the cervical os in women with placenta previa.

Study Design This is a retrospective cohort study of singleton pregnancies with placenta previa undergoing third-trimester ultrasound and delivering at our institution from 2002 through 2011. For study purposes, an investigator measured placental extension, defined as the placental distance from the internal os across the placenta continuing out to the lowest placental edge. If morbidly adherent placentation was suspected, women were excluded. Receiver operating characteristic (ROC) curves were developed for pertinent surgical outcomes, and multivariate analysis was performed to determine the placental extension with the best predictive discriminatory zone.

Results In total, 157 women had placenta previa, ultrasound, and delivery data: 86 (55\%) had a placental extension of $<40 \mathrm{~mm}$, and 71 (45\%) had a placental extension of

Keywords

- ultrasound

- placenta previa

- placental extension

- surgical outcomes

- central previa $\geq 40 \mathrm{~mm}$. Women with placental extension of $\geq 40 \mathrm{~mm}$ had increased surgical time, blood loss $>2,000 \mathrm{~mL}$, blood transfusion, and rate of peripartum hysterectomy. After multivariate analysis, only peripartum hysterectomy and surgical time $>90$ minutes remained significant, $p \leq 0.05$ and $p \leq 0.01$, respectively.

Conclusion In women with placenta previa, the placental extension ultrasound measurement of $\geq 40 \mathrm{~mm}$ is a predictor of adverse surgical outcomes.
\end{abstract}

In a recent report of 4,693 maternal deaths in the United States, placenta previa accounted for $13 \%$ of deaths secondary to hemorrhage, with placenta previa without evidence of morbidly adherent placenta (MAP) accounting for $6 \%{ }^{1}$ The published incidence of placenta previa is approximately 2.8 to 5.5 per 1,000 deliveries $^{2-7}$ and has been associated with higher rates of maternal hemorrhage, maternal blood transfusion, general anesthesia, peripartum hysterectomy, and operative complications. $^{6,8,9}$ Placenta previa is also associated with a high rate of peripartum hysterectomy, which complicates approximately

received

August 4, 2017

accepted after revision

February 23, 2018
DOI https://doi.org/

10.1055/s-0038-1641163. ISSN 2157-6998.
5 to $25 \%$ of pregnancies with placenta previa. This is a morbid procedure associated with major complications such as blood transfusion, reoperation, organ injury, fever, wound infections, venous thromboembolism, and death., ${ }^{4,9-16}$

Although the terminologies marginal, incomplete, and complete placenta previa are no longer used, ${ }^{17}$ having a complete or major placenta previa, when the placenta covers the entire internal cervical os, has been shown to have increased maternal morbidity when compared with an incomplete placenta previa, when the placenta abuts or only partially
Copyright $\odot 2018$ by Thieme Medical Publishers, Inc., 333 Seventh Avenue, New York, NY 10001, USA. Tel: +1(212) 584-4662.
License terms

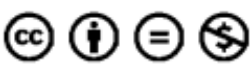


covers the internal cervical os. ${ }^{12,13,18}$ Investigators have also explored pregnancy outcomes in women with placenta previa of different locations, most frequently comparing anterior versus posterior placental locations. ${ }^{19-21} \mathrm{~A}$ central/symmetric placenta previa has been defined as when the placenta has equal portions on the anterior and posterior lower uterine segments on ultrasound assessment of the cervix and lower uterine segment. Although a symmetric previa has been thought to be associated with worse maternal morbidity, actual quantitative data are limited on cesarean delivery outcomes according to the specific distance from where the placenta overlaps the internal cervical os and extends out to the lowest placental edge. ${ }^{19-21}$ Our objective was to evaluate the relationship between the ultrasound measurement of placental extension over the internal cervical os and surgical outcomes in women with placenta previa and no sonographic evidence of MAP.

\section{Methods}

This is a retrospective cohort study of singleton pregnancies delivering a liveborn infant at $\geq 24$ weeks' gestation at a single institution from January 2002 to November 2011. Pregnancies were identified from review of the sonography database, which is managed and accessed only by our departmental epidemiologist. From this database, all patients with a complete previa during this time frame were ascertained, and an ultrasound review was performed by a single sonologist. Only those cases with a complete placenta previa in the third trimester were included. Complete placenta previa was determined when images demonstrated the tissue fully covering the internal os. Women with suspicion of MAP on antenatal sonography were excluded.

The sonologist (A. W.) was blinded to pregnancy outcomes and reviewed all sonographic images. The placental extension in the setting of complete previa was measured in the midline sagittal plane of the cervix and its internal os. The cursors were placed from the internal os to the lowest edge of the placental extension. If the distance was curvilinear, then segmental measurements were obtained to reflect this finding, similar to measurement of the cervical length. Transabdominal and transvaginal examinations were both included (-Figs. 1 and $\mathbf{2}$ ), and the last sonogram prior to delivery was used for analysis. All examinations were performed at our sonography unit by registered diagnostic medical sonographers, and quality assurance was performed by the maternal-fetal medicine and radiology faculty. Our ultrasound unit was accredited by the American Institute of Ultrasound in Medicine throughout the study period.

Medical records were queried to collect maternal demographic characteristics, pregnancy outcome data, maternal complications, postoperative course, and surgical case data including additional procedures performed, operative complications, postpartum hemorrhage, and blood transfusion. Body mass index (BMI) was calculated from height at the first prenatal visit and weight recorded at the last prenatal visit. Tobacco use was based on maternal report. Placental pathology reports were reviewed for each case, and MAP was

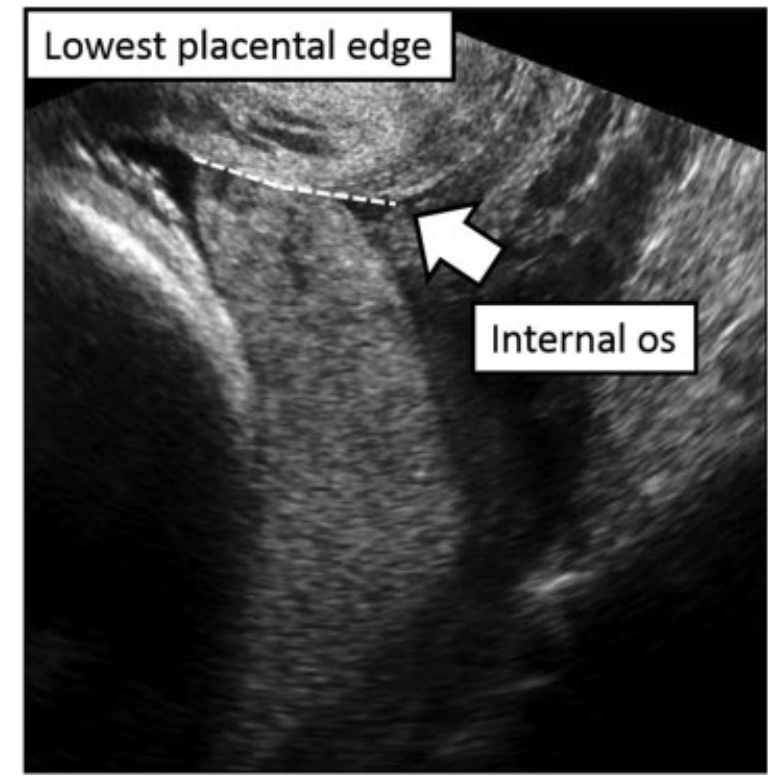

Fig. 1 Transvaginal image with placental extension defined as the distance from where the placenta overlaps the internal cervical os to the lowest placental edge on the sagittal image of the cervix.

confirmed by a standard pathological examination. Postpartum hemorrhage was defined as an estimated blood loss $>1,000 \mathrm{~mL}$ during or following cesarean delivery.

Univariate analysis was performed to develop individual receiver operating characteristic (ROC) curves to estimate the best discriminatory zone for the ultrasound measurement of placental extension in predicting the following key obstetrical outcomes: estimated blood loss $>2,000 \mathrm{~mL}$, blood transfusion, and need for peripartum hysterectomy. To select a threshold cutoff for the os distance, a univariate ROC curve was developed for each of the three outcomes. The

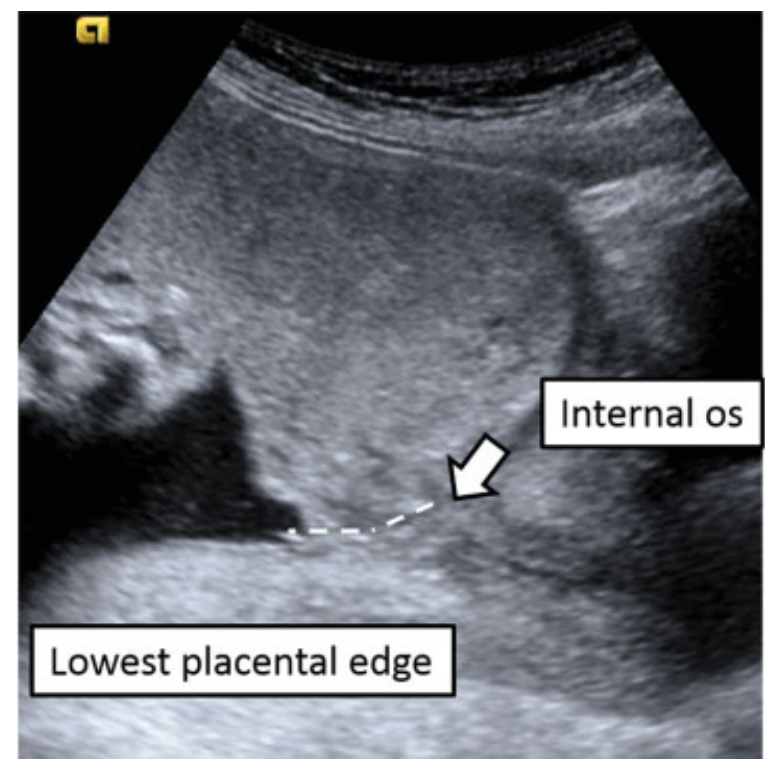

Fig. 2 Transabdominal image with placental extension defined as the distance from where the placenta overlaps the internal cervical os to the lowest placental edge on the sagittal image of the cervix. 
cutoff point was selected to be the point where 1-specificity of 1 is most closely equal to sensitivity. This point corresponds to the point on the univariate ROC curve closes to the upper leftmost point of the figure, specificity of 1 and sensitivity of 1 . Statistical comparisons were made using SAS 9.3 and included Student's $t$-test or Wilcoxon rank-sum test for continuous data with the Shapiro-Wilk test for normality and $\mathrm{X}^{2}$ for categorical data. Logistic regression was also performed to account for background characteristics that could have contributed to significant outcomes. A value of $p<0.05$ was used for significance. The University of Texas Southwestern Medical Center Institutional Review Board approved this study.

\section{Results}

Between 1997 and 2011, a total of 148,031 women delivered a singleton at $\geq 24$ weeks' gestation at our institution, and 300 women had the ultrasound diagnosis of placenta previa. Complete antenatal ultrasound and medical records were available for 214 women, with 47 women having a suspicion of MAP, leaving 157 women for analysis. Eighty-six (55\%) women had a placental extension of $<40 \mathrm{~mm}$, and 71 (45\%) had a placental extension of $\geq 40 \mathrm{~mm}$. The average estimated gestational age at the last ultrasound was 34 weeks $( \pm 2.3$ weeks).

- Table 1 delineates baseline characteristics for our cohort, which comprised predominately multiparous Hispanic women. Univariate analysis was performed to develop individual ROC curves to estimate the best discriminatory zone for the ultrasound measurement of placental extension in predicting key obstetrical outcomes stated previously. The most discriminatory distance as estimated from the univariate ROC curves was equivalent on all three ROC curves and estimated to be $40 \mathrm{~mm}$. Women with a placental extension of $\geq 40 \mathrm{~mm}$ were younger, had a larger BMI, and were more likely to have had a prior cesarean delivery, $\mathrm{p} \leq 0.05$. There was no difference in ethnicity, nulliparity, tobacco use, drug use, or history of prior dilation and curettage between the two groups. Forty-five (29\%) women had predominately anterior placentation, 94 (60\%) had predominately posterior placentation, and 18 (11\%) had predominately lateral placentation (or central/symmetric). Women with a placental extension of $\geq 40 \mathrm{~mm}$ were less likely to have a predominately posterior placenta and more likely to have a lateral or centralized placenta, $p=0.02$.

Pregnancy outcomes are displayed in $\boldsymbol{- T}$ Table $\mathbf{2}$. Women at our institution with placenta previa are delivered between $36^{0 / 7}$ and $38^{0 / 7}$ weeks' gestation. ${ }^{22}$ Thus, we analyzed women delivering at less than 36 weeks for preterm birth; $30(20 \%)$ women met this criterion, with no difference between placental extension groups. There was also no difference in emergent/unplanned delivery secondary to vaginal bleeding from the previa at the time of delivery, with 23 (28\%) women with a placental extension of $<40 \mathrm{~mm}$ having vaginal bleeding and $16(23 \%)$ women with a placental extension of $\geq 40 \mathrm{~mm}, p=0.44$. On histological examination, $5(6 \%)$ of the women with a placental extension of
Table 1 Maternal demographic characteristics in pregnancies with placenta previa according to the placental extension measurement

\begin{tabular}{|c|c|c|c|}
\hline \multirow[t]{2}{*}{ Characteristic } & \multicolumn{2}{|c|}{ Placental extension } & \multirow[t]{2}{*}{$p$-Value } \\
\hline & $\begin{array}{l}<40 \mathrm{~mm}, \\
N=86\end{array}$ & $\begin{array}{l}\geq 40 \mathrm{~mm}, \\
N=71\end{array}$ & \\
\hline Age & $32.0 \pm 6.2$ & $30.2 \pm 4.9$ & 0.049 \\
\hline \multicolumn{4}{|l|}{ Race/ethnicity } \\
\hline Hispanic & $74(86)$ & $61(86)$ & \multirow[t]{4}{*}{0.54} \\
\hline Black & $8(9)$ & $4(6)$ & \\
\hline White & $1(1)$ & $3(4)$ & \\
\hline Other & $3(3)$ & $3(4)$ & \\
\hline BMI, kg/m² & $\begin{array}{l}26.2 \\
{[23.2,30.3]}\end{array}$ & $\begin{array}{l}28.8 \\
{[25.0,31.6]}\end{array}$ & 0.02 \\
\hline Nulliparity & $14(16)$ & $9(13)$ & 0.53 \\
\hline Tobacco use & $3(3)$ & $4(6)$ & 0.52 \\
\hline Illicit drug use & $2(2)$ & $2(3)$ & 0.85 \\
\hline $\begin{array}{l}\text { Prior cesarean } \\
\text { delivery }\end{array}$ & $27(31)$ & $35(49)$ & 0.02 \\
\hline Prior D\&C & $16(19)$ & $16(23)$ & 0.54 \\
\hline \multicolumn{4}{|c|}{ Placental location } \\
\hline Anterior & $22(26)$ & $23(32)$ & \multirow[t]{3}{*}{0.02} \\
\hline Posterior & $59(69)$ & $35(49)$ & \\
\hline Lateral & $5(6)$ & $13(18)$ & \\
\hline
\end{tabular}

Abbreviation: BMI, body mass index; D\&C, dilation and curettage. Note: Data expressed as mean \pm standard deviation, median [Q1, Q3], and $N(\%)$.

Table 2 Pregnancy outcomes in all women with placenta previa placenta according to the placental extension measurement

\begin{tabular}{|c|c|c|c|}
\hline \multirow[t]{2}{*}{ Characteristic } & \multicolumn{2}{|c|}{ Placental extension } & \multirow[t]{2}{*}{ p-Value } \\
\hline & $\begin{array}{l}<40 \mathrm{~mm} \\
N=86\end{array}$ & $\begin{array}{l}\geq 40 \mathrm{~mm}, \\
N=71\end{array}$ & \\
\hline Preterm delivery ${ }^{\mathrm{a}}$ & $15(17)$ & $15(21)$ & 0.56 \\
\hline $\begin{array}{l}\text { Vaginal bleeding } \\
\text { at delivery }\end{array}$ & $24(28)$ & $16(23)$ & 0.44 \\
\hline $\mathrm{EBL}>2,000 \mathrm{~mL}$ & $12(14)$ & $20(28)$ & 0.03 \\
\hline Blood transfusion & $20(23)$ & $28(39)$ & 0.03 \\
\hline $\begin{array}{l}\text { Peripartum } \\
\text { hysterectomy }\end{array}$ & $12(14)$ & $20(28)$ & 0.03 \\
\hline $\begin{array}{l}\text { Length of surgery, } \\
\text { minutes }\end{array}$ & $64[50,85]$ & $72[54,119]$ & 0.01 \\
\hline $\begin{array}{l}\text { Operative } \\
\text { complications }\end{array}$ & $2(2)$ & $4(6)$ & 0.28 \\
\hline $\begin{array}{l}\text { Medical } \\
\text { complications }\end{array}$ & $12(14)$ & $7(10)$ & 0.43 \\
\hline MAP & $5(6)$ & $9(13)$ & 0.13 \\
\hline
\end{tabular}

Abbreviations: EBL, estimated blood loss; MAP, morbidly adherent placentation.

Note: Data expressed as N (\%).

'Preterm delivery less than 36 weeks' estimated gestational age. 
$<40 \mathrm{~mm}$ had MAP compared with 9 (13\%) of the women with a placental extension of $\geq 40 \mathrm{~mm}, p=0.13$.

Thirty-two (20\%) women had a significant estimated blood loss $>2,000 \mathrm{~mL}$ : $12(14 \%)$ of the 86 women with a placental extension of $<40 \mathrm{~mm}$ and 20 (28\%) of the 71 women with a placental extension of $\geq 40 \mathrm{~mm}, p=0.03$ (-Table 2). Blood transfusion requirement was also more common in women with a placental extension of $\geq 40 \mathrm{~mm}$, $p=0.03$. In addition, more of the women with a placental extension of $\geq 40 \mathrm{~mm}$ required a peripartum hysterectomy, 20 (28\%) versus 12 (14\%), respectively, $p=0.03$. Not surprisingly, this group also had an 8-minute-longer median surgical time, $72(54,199)$ versus $64(50,85)$ minutes, $p=0.01$.

In examining cesarean delivery complications, we further recorded operative complications. Six women had operative complications with no difference between the placental extension groups. These included two hematomas (one pelvic, one vaginal cuff), two unplanned unilateral salpingo-oophorectomies, and two reoperations for bleeding. No cystotomy or ureteral injury occurred in this cohort. Nineteen women experienced postoperative complications, with no difference between placental extension groups. Postoperative complications included five cases of metritis, one case of puerperal fever, three cases of wound infections, two cases of transfusion reactions, two women with fluid overload, one case of pulmonary edema, one case of ileus, one case of gluteal abscess, and two women with postpartum hypertensive complications.

Since the placental extension groups differed in maternal age, a history of prior cesarean delivery, and BMI, logistic regression was recorded to adjust for these factors. Odds ratios of having each outcome are shown in - Table 3. The need for peripartum hysterectomy and an increased operative time of more than 90 minutes in women with a placental extension of $\geq 40 \mathrm{~mm}$ remained significant, odds ratio [OR] 2.41 (1.01, $5.75), p=0.48$, and OR $3.08(1.40,6.78), p \leq 0.01$, respectively.

\section{Discussion}

Placental extension of $\geq 40 \mathrm{~mm}$ beyond the internal os in the setting of a placenta previa is a valid predictor of women who will require a peripartum hysterectomy. As a result, these women had longer surgical times but fortunately not increased operative or postoperative complications.

Prior investigators have described high rates of peripartum hysterectomy and bleeding in central previas. ${ }^{21}$ Saitoh et al reported increased rates when two-thirds of the pla- centa overlaps the internal os. ${ }^{23}$ Young et al reported that $50 \%$ of their four "central" previas required hysterectomies and blood transfusions. ${ }^{21}$ This is consistent with our finding that women with a longer placental extension of $\geq 40 \mathrm{~mm}$ have increased rates of peripartum hysterectomy. To our knowledge, a measured distance of how far the placenta extends over and then beyond the internal cervical os to the lowest placenta edge with a numerical threshold developed for poor outcomes has yet to be described.

The majority of prior research on women with placenta previa has concentrated on sonographic prediction of MAP or outcomes in all women with placenta previa, with and without MAP. At our institution, Rac et al recently published the Placental Accreta Index, a tool to stratify individual risk of MAP. ${ }^{24}$ Silver et al investigated the effect of the number of prior cesarean deliveries with and without placenta previa, ${ }^{25}$ and Grobman et al explored pregnancy outcomes for women with placenta previa by number of prior cesarean deliveries. ${ }^{15}$ Although both cohorts had women requiring hysterectomy with placenta previa and no placental invasion/MAP, neither investigator fully explored morbidity in women with placenta previa and no evidence of invasion/MAP. The placental extension measurement is important not only for providing information on the risk of peripartum hysterectomy to patients with a placenta previa and no evidence of an MAP -a population where peripartum hysterectomy is not planned but occurred in 18 (14\%) women in our cohort-but also for providing a quantitative measure in women with complete placenta previa.

A strength of our study is its use of a quantitative measurement rather than a qualitative assessment. The placental extension was able to be obtained from the standard midline sagittal image of the cervix in cases of placenta previa. This measurement can be incorporated into the routine follow-up third-trimester ultrasound in women with placenta previa. In addition, we included only women with a placenta previa where MAP was not suspected. As MAP, regardless of placental location, can be catastrophic, our aim was to have a predictive measure in women where MAP was not thought to be a factor. The main weakness of this study is the reliance on measurements taken from already recorded still images as well as the retrospective data collection. In addition, selecting the cutoff at $40 \mathrm{~mm}$ was accomplished with one dataset without holding out observations for confirmation. We were limited in sample size and propose this cutoff as a recommended cut point to be further evaluated.

Table 3 OR $(95 \% \mathrm{Cl})$ of pregnancy outcomes in women with placenta previa and a placental extension measurement of $\geq 40$ mm

\begin{tabular}{|l|l|l|l|l|}
\hline Outcome & $p$-Value & OR & $p$-Value & Adjusted OR $^{\mathbf{a}}$ \\
\hline EBL $>2,000$ & 0.03 & $2.42(1.09,5.38)$ & 0.08 & $2.16(0.91,5.14)$ \\
\hline Blood transfusion & 0.03 & $2.15(1.08,4.29)$ & 0.07 & $1.99(0.95,4.19)$ \\
\hline Hysterectomy & 0.03 & $2.42(1.09,5.38)$ & 0.048 & $2.41(1.01,5.75)$ \\
\hline Length of surgery $>90$ min & $<0.01$ & $2.79(1.38,5.64)$ & $<0.01$ & $3.08(1.40,6.78)$ \\
\hline
\end{tabular}

Abbreviations: $\mathrm{Cl}$, confidence interval; $\mathrm{EBL}$, estimated blood loss; OR, odds ratio.

${ }^{a}$ Adjusted for age, prior cesarean, and body mass index. These are the odds ratios of having the outcome if placental extension is $\geq 40$ mm as opposed to $<40 \mathrm{~mm}$. 
In conclusion, a placental extension of $\geq 40 \mathrm{~mm}$ is a strong predictor of peripartum hysterectomy and increased operative time in women with a placenta previa without sonographic evidence of MAP. Given the association with adverse surgical outcomes, the quantitative measurement of placental extension in the setting of placenta previa may be preferred over the qualitative descriptions of "symmetric" and "asymmetric" previas. A prospective study examining placental extension in women with placenta previa will further validate its use in clinical practice.

\section{Conflict of Interest}

None.

\section{Note}

This study was presented at the Society for MaternalFetal Medicine 35th Annual Meeting, Poster Session IV, February 2-6, 2015.

\section{References}

1 Berg CJ, Callaghan WM, Syverson C, Henderson Z. Pregnancyrelated mortality in the United States, 1998 to 2005. Obstet Gynecol 2010;116(06):1302-1309

2 Faiz AS, Ananth CV. Etiology and risk factors for placenta previa: an overview and meta-analysis of observational studies. J Matern Fetal Neonatal Med 2003;13(03):175-190

3 Frederiksen MC, Glassenberg R, Stika CS. Placenta previa: a 22-year analysis. Am J Obstet Gynecol 1999;180(6 Pt 1):1432-1437

4 Martin JA, Hamilton BE, Sutton PD, Ventura SJ, Menacker F, Munson ML. Births: final data for 2003. Natl Vital Stat Rep 2005;54(02):1-116

5 Iyasu S, Saftlas AK, Rowley DL, Koonin LM, Lawson HW, Atrash HK. The epidemiology of placenta previa in the United States, 1979 through 1987. Am J Obstet Gynecol 1993;168(05):1424-1429

6 Rosenberg T, Pariente G, Sergienko R, Wiznitzer A, Sheiner E. Critical analysis of risk factors and outcome of placenta previa. Arch Gynecol Obstet 2011;284(01):47-51

7 Cunningham FG. Obstetrical hemorrhage. In: William's Obstetrics. 24rd edition. New York, NY: McGraw-Hill Medical; 2014:799-804

8 Onwere C, Gurol-Urganci I, Cromwell DA, Mahmood TA, Templeton A, van der Meulen JH. Maternal morbidity associated with placenta praevia among women who had elective caesarean section. Eur J Obstet Gynecol Reprod Biol 2011;159(01):62-66

9 Crane JMG, Van den Hof MC, Dodds L, Armson BA, Liston R. Maternal complications with placenta previa. Am J Perinatol 2000;17(02):101-105

10 Shellhaas CS, Gilbert S, Landon MB, et al; Eunice Kennedy Shriver National Institutes of Health and Human Development MaternalFetal Medicine Units Network. The frequency and complication rates of hysterectomy accompanying cesarean delivery. Obstet Gynecol 2009;114(2 Pt 1):224-229
11 Wright JD, Devine P, Shah M, et al. Morbidity and mortality of peripartum hysterectomy. Obstet Gynecol 2010;115(06): 1187-1193

12 Choi SJ, Song SE, Jung KL, Oh SY, Kim JH, Roh CR. Antepartum risk factors associated with peripartum cesarean hysterectomy in women with placenta previa. Am J Perinatol 2008;25(01):37-41

13 Daskalakis G, Simou M, Zacharakis D, et al. Impact of placenta previa on obstetric outcome. Int J Gynaecol Obstet 2011;114(03): 238-241

14 Giambattista E, Ossola MW, Duiella SF, et al. Predicting factors for emergency peripartum hysterectomy in women with placenta previa. Arch Gynecol Obstet 2012;285(04):901-906

15 Grobman WA, Gersnoviez R, Landon MB, et al; National Institute of Child Health and Human Development (NICHD) Maternal-Fetal Medicine Units (MFMU) Network. Pregnancy outcomes for women with placenta previa in relation to the number of prior cesarean deliveries. Obstet Gynecol 2007;110(06):1249-1255

16 Yaegashi N, Chiba-Sekii A, Okamura K. Emergency postpartum hysterectomy in women with placenta previa and prior cesarean section. Int J Gynaecol Obstet 2000;68(01):49-52

17 Reddy UM, Abuhamad AZ, Levine D, Saade GR; Fetal Imaging Workshop Invited Participants. Fetal imaging: Executive summary of a Joint Eunice Kennedy Shriver National Institute of Child Health and Human Development, Society for Maternal-Fetal Medicine, American Institute of Ultrasound in Medicine, American College of Obstetricians and Gynecologists, American College of Radiology, Society for Pediatric Radiology, and Society of Radiologists in Ultrasound Fetal Imaging Workshop. Am J Obstet Gynecol 2014;210(05):387-397

18 Tuzovic L. Complete versus incomplete placenta previa and obstetric outcome. Int J Gynaecol Obstet 2006;93(02):110-117

19 Baba Y, Matsubara S, Ohkuchi A, et al. Anterior placentation as a risk factor for massive hemorrhage during cesarean section in patients with placenta previa. J Obstet Gynaecol Res 2014;40(05): 1243-1248

20 Hasegawa J, Matsuoka R, Ichizuka K, et al. Predisposing factors for massive hemorrhage during Cesarean section in patients with placenta previa. Ultrasound Obstet Gynecol 2009;34(01):80-84

21 Young BC, Nadel A, Kaimal A. Does previa location matter? Surgical morbidity associated with location of a placenta previa. J Perinatol 2014;34(04):264-267

22 American College of Obstetricians and Gynecologists. ACOG committee opinion no. 560: Medically indicated late-preterm and early-term deliveries. Obstet Gynecol 2013;121(04):908-910

23 Saitoh M, Ishihara K, Sekiya T, Araki T. Anticipation of uterine bleeding in placenta previa based on vaginal sonographic evaluation. Gynecol Obstet Invest 2002;54(01):37-42

24 Rac MWF, Dashe JS, Wells CE, Moschos E, McIntire DD, Twickler DM. Ultrasound predictors of placental invasion: the Placenta Accreta Index. Am J Obstet Gynecol 2015;212(03):343.e1-343.e7

25 Silver RM, Landon MB, Rouse DJ, et al; National Institute of Child Health and Human Development Maternal-Fetal Medicine Units Network. Maternal morbidity associated with multiple repeat cesarean deliveries. Obstet Gynecol 2006;107(06):1226-1232 